\section{University of New Hampshire}

Carsey School of Public Policy

\section{CARSEY RESEARCH}

National Fact Sheet \#29

Summer 2015

\title{
Diversity Growing Because Births Far Exceed Deaths Among Minorities, But Not Among Whites
}

Kenneth M. Johnson

$\mathrm{T}$ The growing diversity of the U.S. population evident in new Census Bureau estimates reflects two important demographic trends. The minority population is growing and the non-Hispanic white population is not. This interplay of white and minority population change is fueling the growing diversity of the U.S. population. The minority population is growing both because births far exceed deaths and because there is significant immigration. In contrast, growth has been minimal among the non-Hispanic white population because aging has reduced births and increased deaths.

The distinctly different demographic trajectories among whites and minorities are driven by the interaction of several key demographic forces. Natural increase (births to deaths) is the major force behind

\section{FIGURE 1. MOST BIRTHS ARE MINORITY, MOST DEATHS ARE WHITE}
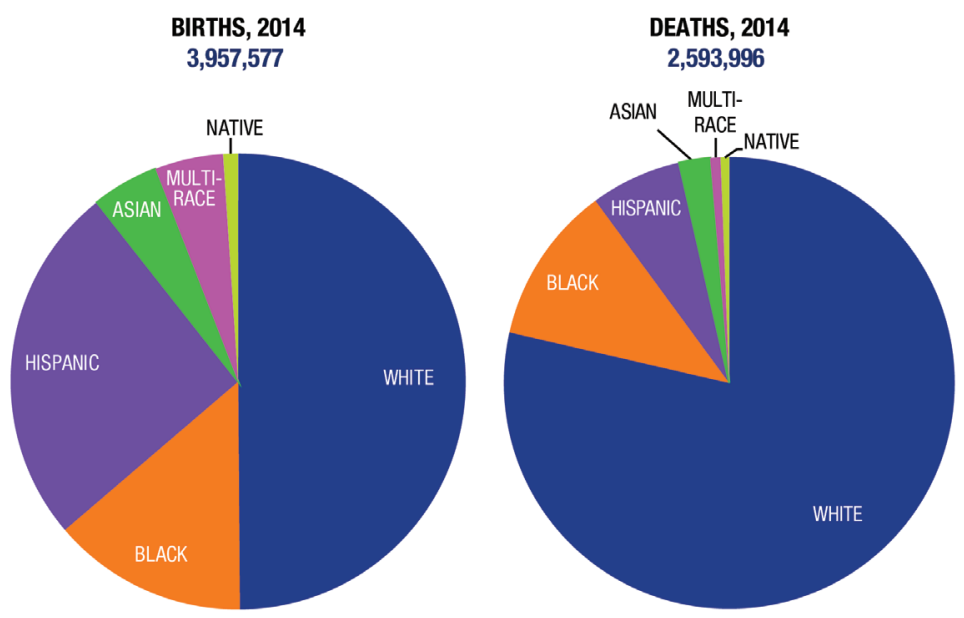

Source: Census Bureau Estimates, 2014

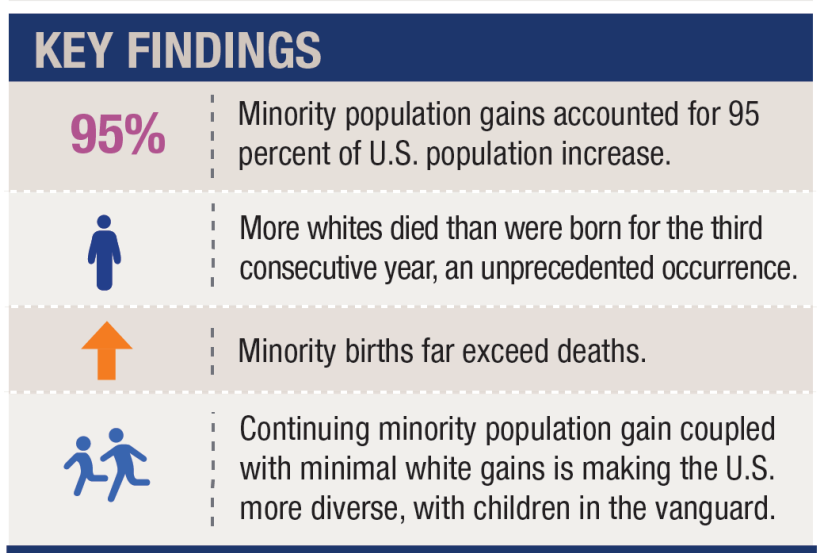

the growing diversity of the U.S. population, though immigration remains important. Although the pace of U.S. population growth is slowing because of the lingering impact of the Great Recession and the aging of the population, the population continues to become more diverse. This will produce a rich tapestry of demographic change in the United States over the next several decades.

The importance of natural increase to the growing diversity of the U.S. population is clearly evident among non-Hispanic whites. Currently, whites account for 78 percent of all U.S. deaths, but less than 50 percent of births. In each of last three years, more non-Hispanic whites died than were born. Such natural decrease is without precedent in U.S. history. Between July of 2013 and July of 2014, there were 2,036,000 non-Hispanic white deaths, but only $1,975,000$ births. So, deaths exceeded births by 62,000 . This gap is wider than last year, when there were $1,980,000$ non-Hispanic white births compared to $2,007,000$ deaths: a difference of 27,000 . The nonHispanic white population did increase slightly each 
year, but only because of immigration. The immigration gain was 155,000 between July of 2013 and 2014. So, the non-Hispanic white population grew by just 94,000 (.04 percent). Ironically, non-Hispanic whites are now more dependent on immigration for population increase than any other group. Though non-Hispanic white natural increase may occur again as fertility rates recover from the economic downturn, it is likely to be short-lived because the population is aging rapidly.

Minority populations produced the vast majority of the nation's population increase between 2013 and 2014. Nearly 95 percent of the U.S. population gain of $2,360,000$ came from minorities. The minority population grew by 1.9 percent in the last year. Hispanics fueled nearly half of this gain. Asians and African Americans also made significant contributions to the recent growth of the U.S. population.

The driving force behind the growth of minority population is natural increase. Currently, there are 3.6 minority births for every death. Among Hispanics, the ratio is even higher at 6.0 births per death. In contrast, the ratio of births to deaths is currently less than 1 (.97) among non-Hispanic whites according to Census Bureau estimates. There are many more births than deaths among minorities because the minority population (with the exception of Asians) is on average more than ten years younger than the non-Hispanic white population (median age 43 ). This results in more women of child-bearing age and fewer older adults at high risk of mortality. Some minority women, notably Hispanics, also have higher fertility rates than other groups. High birth to death ratios produce substantial population increase. Between 2013 and 2014, 63 percent of the minority population increase came from natural increase. Among Hispanics, natural increase accounted for 73 percent of the population increase. Though Hispanic immigration remains an important policy issue, it is natural increase that is now producing the majority of all Hispanic population increase.

The growth of the minority population combined with stagnation of the non-Hispanic white population continues to increase the diversity of the population. Minorities currently represent 38 percent of the U.S. population. By 2045, Census projections suggest that no group will constitute a majority of the U.S. population. The U.S. population is becoming more diverse from youngest to oldest with children in the vanguard. This year, minority births exceeded those to non-Hispanic whites, and the majority of children under age 5 are now minority. Though diversity is greatest among infants, nearly 48 percent of those under age 20 are minority. In contrast, 78 percent of the population over 65 is non-Hispanic white and projections suggest that whites will constitute the vast majority of the older population for the foreseeable future. Growing child diversity is fueled both by more minority children and by fewer non-Hispanic white children. For example, between 2000 and 2014, the minority child population grew by 27 percent, while the non-Hispanic white child population diminished by nearly 13 percent. These changes reflect the differential impact of population aging on women of child-bearing age. There were 9 percent fewer white women of prime child-bearing age in 2014 than in 2000, while there are 22 percent more minority women in this age group. These changes, coupled with higher fertility rates among some minority groups, have made children the leading edge of an increasingly diverse society. Even though the Great Recession has slowed both the number of births and fertility rates among young women, the U.S. population continues to grow and become more diverse.

\section{Data}

This analysis is based on Census Bureau projections and population estimates released on June 25, 2015. The classification of births and deaths by race in Census Bureau estimates differ from the procedures used by the National Center for Health Statistics. Thus, there are differences in the number of births and deaths classified by race/Hispanic origin by the two agencies. NCHS data does not allow for multiple race births or deaths - all births and deaths are classified to one race category. Census allows two or more races. NCHS data consistently show more non-Hispanic white births than Census data. Readers should exercise caution in the interpretation of these results and recognize that this analysis is indicative of current trends using the best data available at this time.

\section{About the Author}

Kenneth M. Johnson is senior demographer at the Carsey School of Public Policy and professor of sociology at the University of New Hampshire (ken.johnson@unh.edu).

\section{A cknowledgments}

The author thanks Michael Ettlinger, Amy Sterndale, Bianca Nicolosi, and Laurel Lloyd at the Carsey School of Public Policy at the University of New Hampshire for their thoughtful comments and suggestions. 